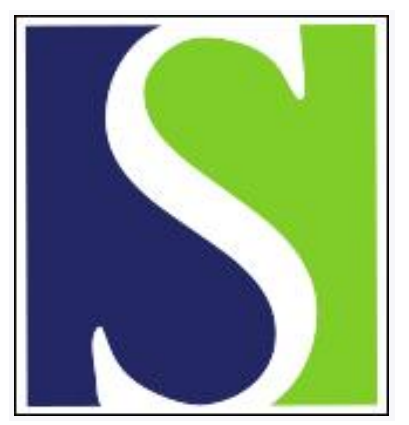

Scand J Work Environ Health 2009;35(2):127-135

https://doi.org/10.5271/sjweh.1308

Published online: 17 Mar 2009, Issue date: 00 Mar 2009

Exploring gender, work and living conditions and health suggestions for contextual and comprehensive approaches

by Härenstam $A$

Affiliation: Department of Work Science, University of Göteborg, PO Box 705, SE-405 30 Göteborg, Sweden. annika.harenstam@av.gu.se

Refers to the following texts of the Journal: 2008;34(2):81-82

2001;27(5):354-357

Key terms: cluster analysis; comprehensive approach; contextual approach; discussion paper; epidemiology; gender; gender-based analysis; health; holistic approach; living conditions; multilevel analysis; occupational health; woman; work

This article in PubMed: www.ncbi.nlm.nih.gov/pubmed/19294318 


\title{
Exploring gender, work and living conditions, and health - suggestions for contextual and comprehensive approaches
}

\author{
by Annika Härenstam, $P h D^{1}$
}

\begin{abstract}
Härenstam A. Exploring gender, work and living conditions and health - suggestions for contextual and comprehensive approaches. Scand J Work Environ Health. 2009;35(2):127-133.

New methods are needed to complement traditional epidemiological methods in the analyses of complex multivariate exposures. Contextual and comprehensive analyses such as multilevel and cluster analyses are particularly suitable for comparisons of women's and men's risk factors for health in working life as well as for guidance in preventive action. Such methodologies are presented in this discussion paper. Contextual and comprehensive (or holistic) approaches help identify the gender-structured situations for women and men and facilitate the discovery of differences among all women and all men. Empirical studies using these approaches show that it is important to take gender composition in both the workplace and the sector into consideration when exploring risk factors for health.
\end{abstract}

Key terms cluster analysis; epidemiology; gender-based analysis; holistic approach; multilevel analysis; occupational health; woman.

Exploring the significance of gender in quantitative studies, such as in epidemiology, job stress research, and ergonomics, is a considerable challenge from a theoretical and methodological point of view. Both work and private life are gender segregated. The gender order is embedded in daily work, organizational practices, the labor market, social institutions, and society as a whole. Therefore, gender is associated with a wide range of contextually and individually related exposures, in addition to being related to factors that are linked to gender differences in health outcomes. Consequently, it is very difficult to compare women and men with regard to differences in risk factors for health. The larger the overall difference, the more difficult it is to differentiate for all women in traditional epidemiological analyses.

In order that the knowledge of female versus male risk factors for health can be improved in quantitative occupational health studies, an analysis strategy that considers the complexity and context of women's and men's overall situations is necessary. In this paper, two analytical strategies and methodologies are presented that aim to strengthen the contextual and comprehensive perspective in occupational health science. They are labeled as either a holistic or a comprehensive approach and use pattern analysis (such as cluster analysis) or are contextual in that they apply multilevel modeling. Both of these methodologies were presented and discussed at the V International Congress Women, Work and Health, held in Zacatecas, Mexico, in October of 2008 (unpublished data: Härenstam A. Gendered organizational and working conditions, and women's and men's health. V International Congress on women, Work and Health, Zacatecas, Mexico, October 2008).

\section{Exploring gender differences in occupational health science}

Some decades ago, occupational health research was criticized for either not studying women at all or just "controlling" for gender in the analyses (1-3). In a report from the World Health Organization in 2006

1 University of Göteborg, Department of Work Science, Sweden, and Karolinska Institutet, Department of Public Health Science, Division of Occupational Medicine, Stockholm, Sweden.

Reprint requests to: Professor Annika Härenstam, Department of Work Science, University of Göteborg, PO Box 705, SE-405 30 Göteborg, Sweden. [E-mail: annika.harenstam@av.gu.se] 
(4), recommendations concerning research and policy from a gender perspective were presented. The authors suggested the adoption of new approaches, for example, by collecting gender-disaggregated data on work-related exposures including within the informal economic and the domestic spheres. They also recommended that interdisciplinary research with strong epidemiological, biological, and social science components be carried out.

Since the 1990s, many researchers have made important contributions that have helped to strengthen the gender perspective in occupational health science. Women are now included in most studies, the choice of variables regarding both exposures (such as psychosocial factors and unpaid work) and outcomes (such as musculoskeletal and psychological symptoms) being more relevant to, and having a greater impact on, women. The advantages and disadvantages of gender-integrated (controlling for gender and including interactions in the model) and gender-segregated (stratifying by gender) analyses have been tested. It is recommended that the analyses be stratified by gender so that gender-specific risk factors can be revealed and possible mechanisms underlying the associations among gender, risk factors and health can be explored (3). These developments are important, but they do not solve all the problems of comparing women and men, nor do they take contextual factors into account.

The dominant type of analysis is still multivariate regression. Gender-integrated analyses, including contextual factors and interactions between determinants and gender, are problematic since such models would have to include so many variables that power may be lost and gender-specific risk factors may go undetected. Gender-stratified analyses contribute with knowledge on gender-specific risk factors. However, gender comparisons are difficult and therefore have implications with regard to interventions if different risks are shown for women and men.

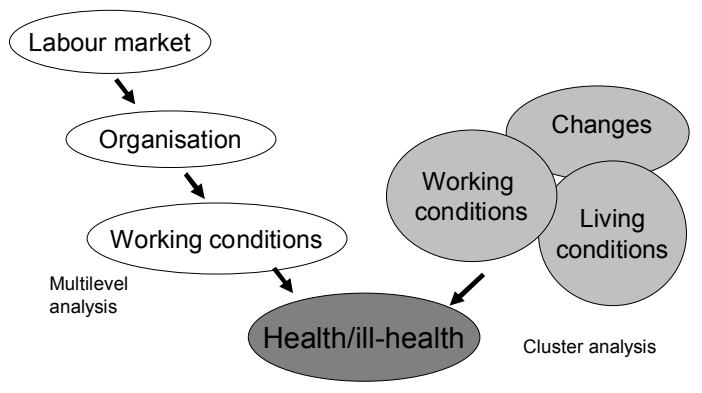

Figure 1. Contextual and comprehensive analyses
The main problem is that multivariate regression is a variable-oriented and reductionistic approach. One disadvantage of adopting such an approach lies in the questionable generalizability of the results. Certain wellknown risk factors may not have the same association with health for all women and men regardless of the context. Another disadvantage lies in the difficulty of exploring the impact of contextual conditions. Discussions about methods and analysis strategies in epidemiology have taken place both nationally and internationally, and "risk-factor epidemiology" is still predominant (5). The risk factors identified in traditional epidemiological studies reinforce an individualistic perspective when applied to risk-factor modification $(6,7)$. Questions such as "Where are the risk factors located?" and "What do they mean in different contexts?" are difficult to answer from analyses based on a variable approach.

\section{Contextual and comprehensive approaches}

If the context is to be taken into account, there are several alternatives to the traditional variable-oriented approach. Relevant structural factors that may have an impact on how women's and men's working and living conditions are shaped should be sought in order to understand how these in turn affect health. We also need to take the complexity of women's and men's working and living conditions into account by applying an analysis strategy that is multifaceted and comprehensive. These two strategies are illustrated in figure 1 .

\section{Multilevel analysis}

Organizations are mediators between societal changes and individuals. There are theoretical support and empirical evidence for organizational determinants of job stress (8-10). An organizational approach in occupational health studies facilitates evaluations of exposure-outcome relationships in the light of contextual (higher-level factors); in other words, potential effect modification can be estimated. The organization of work at the workplace level and work practices at the individual level are significantly interdependent. It is more or less taken for granted that the organization matters, but very little is known about which organizational factors are the most important or what the extent of the impact will be on variance at an individual level. If there are systematic differences in the organization of work between sectors of the labor market, there are also systematic differences in working conditions that would affect women and men differently since the labor market 
is gender segregated. For example, if negative changes are implemented in female- but not male-dominated sectors, the result would be deteriorated work conditions and increased ill-health for the female compared with the male workforce. Such a trend has been taking place in Sweden since the mid-1990s (11). Therefore, structural factors should be sought in the organization of work in different industries or sectors of the labor market rather than only explanations being sought for ill-health at the individual level.

The integration of organizational-level data in occupational health science facilitates the use of research results that can be used for intervention and prevention. The main target for interventions should be the workplace, as it is an arena in which action can be taken that has an impact on many employees. When aiming to identify risk factors and using the knowledge for intervention and prevention, factors describing conditions at the organizational level have to be taken into account $(8,9,12)$.

A contextual and organization-oriented approach in the search for explanations to gender differences in health can be conducted in several ways. One method is to use multilevel analyses of large samples of workplaces and employees. Multilevel modeling has become increasingly common in public health and occupational health science. Such a methodology is recommended when data are hierarchically ordered, such as for individuals in communities or workers in workplaces. With the application of multilevel modeling, contextual factors are taken into account and result in more precise estimates of the impact of exposures than traditional regression analyses in which contextual factors (such as the labor market and organizational conditions) are disaggregated to the individual. Even more important is the fact that determinants can be sought "upwards" in structural conditions in the workplace, the sector, and society.

One advantage of multilevel analysis is that compositional effects can be detected, that is, the compositions of individuals who are grouped together in the same context (eg, the workplace). In multilevel analyses, the effect of being a woman or a man in a female-gendered situation can be determined, and likewise in a malegendered situation (13-15).

In social and public health sciences, many studies investigating the impact on health of, for example, neighborhood characteristics have explored gender differences $(16,17)$. In organizational research, multilevel modeling is common nowadays. However, gender differences in working conditions and health have been explored only in a couple of Swedish studies. In the so-called MOA study (modern work and living conditions for women and men), this methodology was applied $(18,19)$. In the Healthy Workplace study, researchers further developed the same approach by applying multilevel analyses for exploring risk factors for health and health outcomes (20). Together, these two studies identified several structural and organizational characteristics that affect women and men differently and contribute to increased gender differences in work conditions and health risks. The multilevel analyses showed, for example, that there was less influence over work in female-dominated workplaces than in maledominated ones and less development opportunities for women in male-dominated ones $(18,19,21,22)$. Both women and men were affected in a similar way when they worked at the same workplace and in the same sector. However, there were indications that the gender in the minority was more significantly affected $(18,19)$. The results can be interpreted as illustrations of how gender is constructed in work organizations. The results from the multilevel analyses were confirmed and more thoroughly investigated in qualitative studies $(23,24)$. The following are factors that differed systematically between male- and female-dominated organizations at the workplace level: (i) managerial strategies (active versus passive), (ii) principles for the control and measurement of goal fulfillment, (iii) work schedules, hours of work, and job contract, (iv) resource allocation, (v) arenas for dialogue and participation, (vi) division of work (vertical and horizontal), (vii) rationality for actions and priorities of job tasks, and (vii) communication cultures.

\section{Cluster analysis}

Occupational health psychology experts have called for contextual, comprehensive, and ecological approaches to stress models and prevention strategies (25). When working and living conditions are studied from a comprehensive and holistic perspective, the whole situation - both within and outside paid work - is taken into account. Adopting a holistic perspective means that information on social, psychological, ergonomic, physical, and chemical conditions in both work and non-work activities can be integrated into the same analysis. Thus, a situation reflecting a wide range of aspects of each person's work and living conditions constitutes the unit of analysis.

Pattern analysis is an overall concept for multivariate techniques aimed at analyzing multifaceted phenomena and identifying groups of observations with similar characteristics. Cluster analysis is one of the most commonly used techniques. This method seeks a solution with "between-group" differences as large as possible and simultaneously with "within-group" differences as small as possible with regard to all variables included in the cluster analysis $(26,27)$. 
Pattern, or cluster, analysis contributes with "images" of contexts and situations rather than abstract phenomena. This type of knowledge forms a basis for action, and facilitates understanding and application for practitioners, experts, and policy-makers working with interventions and prevention in working life. Arvid Carlsson, the Nobel Prize winner in medicine in 2000, said that pattern analysis "... is like how our brain works. The brain has a unique ability to see patterns in order to recognize for example a face. In a similar manner, we collect all available data and analyse them simultaneously. This is how new associations and patterns are discerned that otherwise would have been disguised for us" (28).

Cluster analyses are often used in generating hypotheses but can, in combination with other methods, be used for testing hypotheses and deepening the knowledge of complex associations. Cluster analysis is particularly suitable when focusing on settings rather than risk factors (29). With such a method, gender stereotyping is avoided, as several different types of situations for both men and women are identified. The comprehensive and holistic approach is useful when the research questions are "what", "where", and "who". In this manner, risk situations and health-promoting situations are identified as opposed to specific risk factors. This is a way to find, for example, target groups for intervention since groups of individuals with different health risks are defined directly from the study population. Traditional epidemiological methods identify specific exposures that are hazardous to health. With such an approach, there is still a long way to go towards identifying contexts in which these risk factors are the most prevalent.

\section{Empirical studies}

For some time now, cluster analysis has been used in public health science and other disciplines, such as psychology, sociology, biology, and economics. For example, cluster analyses contributed to an increased understanding of the complex relationship between work and private life for women and men $(30,31)$. Cluster analysis has been used for the identification of patterns of development of deviant behavior among young adults (32). Within health sciences, cluster analyses have been used to identify different types of musculoskeletal pain syndromes (33). Analyses of associations between patterns of well-being and social circumstances have resulted in more evident and stronger associations than a traditional variable approach (34). The MOA project (35) aimed at developing a multivariate approach to occupational health studies that is: (i) capable of identifying groups with similar work conditions, (ii) relevant for studies of associations between work and living conditions, and health, and (iii) appropriate as a basis for preventive actions. Cluster analyses were applied to a variety of aspects of work and living conditions. The technical procedure for the cluster analysis has been described elsewhere (35).

The focus was very broad, covering both the private and the work spheres. The final analysis produced eight clusters, denoted according to their best-defining characteristic (ie, "decent", "boundary-less", "locked", "exposed", "heavy and monotonous", "changed", "mobile", and "restrained"). The next step was to seek an answer to the question: "Where are the clusters found?" This step was addressed by investigating whether the clusters congregated in specific areas of the labor market, such as specific industrial sectors, trades, occupations, and types of work organizations. Furthermore, the clusters were compared with reference to individual characteristics, such as demographic data and lifestyle factors. Finally, the investigation focused on whether there were differences between the clusters regarding health. The following three ill-health variables were tested: (i) psychological distress, (ii) an index of musculoskeletal symptoms, and (iii) a questionnaire item on self-reported general health. The overall model is presented in figure 2 .

The clusters differed with regard to "what" characterized work conditions, "where" in the labor market they were found, and "who" were clustered in these groups. The holistic approach revealed conditions that were important for health and had a higher explanatory power in relation to ill-health than the application of socioeconomic groupings or the demand-control-

Figure 2. Analysis model with a holistic and comprehensive approach (the MOA study).

\begin{tabular}{|l|c|c|}
\hline $\begin{array}{c}\text { 2. Where are the } \\
\text { clusters? }\end{array}$ & $\begin{array}{c}\text { 1. What are the } \\
\text { characteristics of the } \\
\text { clusters? }\end{array}$ & $\begin{array}{c}\text { 3. Who are found in the } \\
\text { clusters? }\end{array}$ \\
\hline $\begin{array}{l}\text { Labour market } \\
\text { Workplace } \\
\text { Occupations }\end{array}$ & $\begin{array}{c}\text { The individual's living and } \\
\text { working conditions }\end{array}$ & $\begin{array}{c}\text { Demographics } \\
\text { Lifestyle }\end{array}$ \\
\hline \multicolumn{3}{|c|}{$\begin{array}{c}\text { 4. Consequences } \\
\text { Health and ill-health } \\
\text { income } \\
\text { work-life balance }\end{array}$} \\
\hline
\end{tabular}


support model. It showed how psychosocial, ergonomic-physical, and occupational hygiene factors combine and interact to create settings with different risks of ill-health (35).

The same model was used in a subsequent study aimed at identifying target groups for the prevention of musculoskeletal disorders (36). This study assessed 15 variables on ergonomic physical exposures, psychosocial exposures, worktime, and demands, and physical effort in the domestic domain. It identified 11 clusters that differed with regard to health risks, demographic data, and physical training. A follow-up study analyzed responses to a questionnaire five years from baseline (37). The aim was to investigate whether different combinations of work and living conditions are associated with neck-shoulder or low back disorders and identify target groups for the prevention of musculoskeletal disorders. Logistic regressions were used to determine whether the 11 clusters from the baseline study differed with regard to musculoskeletal disorders. The results showed that gender-specific working and living conditions (both male- and female-dominated) were associated with increased risks. The conclusion was that, by classifying individuals via a broad variety of exposures, the contextual method facilitates a selective approach for preventive actions in the most appropriate target groups (37).

The contextual and comprehensive approach, developed in the MOA study has also been applied in a cohort survey study (38). Cluster analysis was performed with ten indices on: (i) hours of paid and unpaid work, (ii) time for recreation, (iii) work schedule, (iv) physical workload, (v) mental demands, (vi) emotional demands at work, (vii) time-boundness, (viii) learning possibilities, (ix) influence, and (x) development at work. The cluster analysis identified 13 clusters which were compared with regard to structural factors, demographic factors and consequences. The results showed that gender and class were interrelated and helped to explain risks and possibilities for different groups. Gender differences were mainly explained by the fact that women and men were found in different clusters. Men in the female-dominated situations had similar negative experiences as women in minority situations. Regardless of the socioeconomic position, situations typical for women had the highest risks of ill-health and low salary. Situations typical for men with a low level of education had increased risks of low employability and job satisfaction. Many highly educated men experienced a very healthy situation at work and were found in higher, male-dominated positions or in maledominated industries. The best situation was, however, found in gender-mixed situations.

\section{Comments on the method}

To enable the interpretation of the emerging clusters, it is important to carefully choose the data to be included in any cluster analysis. If the results are intended to be used as a basis for intervention, a contextual approach is necessary. The use of this approach implies that priority be given to aspects that are possible to address. Accordingly, it is important to exclude individual characteristics in the cluster analysis (such as gender, age, and ethnicity) in the search for situations in worklife which bear different health risks. Instead, on the basis of both women's and men's situations, clusters are compared with regard to demographic data, such as the distribution of women and men, age, and education level. If this procedure is adopted, structuring processes can be discovered if there are systematic differences in the distribution between the clusters. This possibility relates to the preceding discussion about where to look for explanations of ill-health, namely, "upstream" or "downstream" (14). The aforementioned strategy was to look primarily for "upstream" explanations (such as organizational and labor market conditions). The main advantage of a cluster analysis is that it is an alternative way of classifying complex data. The method illustrates situations and groups, rather than specific factors, and facilitates the detection of factors that may have different impacts in varying situations. Furthermore, practitioners and policy-makers can more easily interpret and understand the presentation of situations rather than factors and abstract variables unrelated to the context. Therefore, results from pattern analyses inspire reflection and active participation in intervention. The main disadvantage is that pattern analysis is an explorative method. It has to be supplemented with other methods in order to test hypotheses and investigate statistical associations with health outcomes. Consequently, this method does not replace traditional epidemiological methods, rather it complements them.

\section{Discussion}

As the labor market is gender segregated, women and men are exposed to different risks. There are differences in working conditions and health based on gender, age, ethnicity, and social class in most studies. These differences cannot only be explained by traditional methodological approaches. If we take gender segregation into account, the studies referred to in this discussion paper show systematic, structural conditions that affect women and men differently. Therefore, it is valuable to take a contextual perspective in studies of risk factors for women and men when the effect of work and living 
conditions is analyzed and understood with respect to the health of both genders.

The main advantage of applying multilevel analysis is that determinants of differences in health, for example, between women and men, can be sought on a higher level in contextual factors, such as in organizations or communities. This methodology facilitates the avoidance of an individualization of risk factors that might disguise gendering factors and processes in working life. However, when searching databases, we found that multilevel analyses are very rare in studies on the organizational impact of gender differences on working conditions and health. Nevertheless, the method is well-suited to the detection of interactions between, for example, gender composition in the workplace and other factors such as individual gender (13-15). In public health studies, as well as in education science, these types of research questions are very common when the impact of the context on gender differences is explored with respect to the outcome.

A holistic and comprehensive perspective contributes to a deepened understanding of how gender, class, and ethnicity together lead to different positions in working life. A cluster analysis can visualize variations in women's and men's situations in working life instead of generalizing risk factors for all women and men. It means that this type of analysis approach can contribute to the solution of some of the problems of comparing women and men in occupational health studies. In addition, this type of analysis facilitates the use of research findings in intervention and prevention in working life.

A cluster analysis regards and handles a great number of variables simultaneously. The analysis does not identify risk factors, instead, situations are identified that can be used in traditional regression analyses as indicators for situations that constitute different risks for ill-health (or are dissimilarly health promoting).

In applied occupational health science, contextual analyses (such as multilevel modeling) and holistic, comprehensive analyses (such as cluster analysis) are in line with "good practice". Some of the most efficient strategies for the successful prevention of ill-health identified in research include adequate risk analysis and intervention measures adapted to actual problems $(39,40)$. If actions are initiated at a contextual level, knowledge is required concerning what characterizes at-risk groups and where these groups are located. Such preventive strategies may be even more efficient than traditional risk-factor modifications (7). Accordingly, a holistic, multivariate approach that seeks complex patterns of relations and a contextual approach, including organizational-level conditions, that seeks contextual, higher level determinants can be valuable complements to a traditional risk-identifying approach.

\section{Concluding remarks}

Contextual and comprehensive analyses such as the two approaches presented in this discussion paper are particularly suitable when comparing male and female risk factors for health in working life. They also can act as a guide in the development of preventive action. Both approaches enable the identification of gender-structured situations and facilitate an understanding of differences among women and men. Empirical studies grounded in these approaches highlight the importance of considering gender composition in both the workplace and the sector when exploring risk factors for health.

\section{References}

1. Ekenvall L, Härenstam A, Karlqvist L, Nise G, Vingård E. Kvinnan i den vetenskapliga studien - finns hon? [Does the woman exist in scientific studies?] Läkartidningen. 1993;90;3773-4.

2. Messing K, Punnett L, Bond M, Alexanderson K, Pyle J, Zahm S, et al. Be the fairest of them all: challenges and recommendations for the treatment of gender in occupational health research. Am J Ind Med. 2003;43:618-29.

3. Messing K, Tissot F, Stock S. Should studies of risk factors for MSDs be stratified by gender?: lessons from analyses of musculoskeletal disorders among respondents to the 1998 Québec Health Survey. Scand J Work Environ Health. 2009;35(2):96-112.

4. Messing K, Östlin P. Gender equality, work and health: a review of the evidence. Geneva: World Health Organization (WHO), WHO Press; 2006.

5. Susser M. Should the epidemiologist be a social scientist or a molecular biologist? Int J Epidemiol. 1999;28:1019-21.

6. Lindbladh E, Lyttkens CH, Hansson BS, Östergren P-O. Equity is out of fashion?: an essay on autonomy and health policy in the individualized society. Soc Sci Med. 1998;46:1017-25.

7. Lomas J. Social capital and health: implications for public health and epidemiology. Soc Sci Med. 1998;47:1181-8.

8. MacDonald L, Härenstam A, Warren N, Punnett L. Incorporating work organization into occupational health research. Occup Environ Med. 2007;65:1-3.

9. Härenstam A. Organizational approach to studies of job demands, control and health. SJWEH Suppl. 2008;(6):144-9.

10. Piirainen H, Räsänen K, Kivimäki M. Organizational climate, perceived work-related symptoms and sickness absence: a population-based survey. J Occup Environ Med. 2003;45(2):175-84

11. Härenstam A, MOA Research Group. Different development trends in working life and increasing occupational stress require new work environment strategies. Work. 2005;39:261-77.

12. Hagberg M, Punnett L, Bergqvist U, Burdof A, Härenstam A, Kristensen TS, et al (reporters). Broadening the view of exposure assessment [consensus report]. Scand J Work Environ Health. 2001;27(5):354-7.

13. Rousseau D. Issues of level in organizational research. London: JAI press, ltd; 1985. Research in Organizational Behaviour, volume 7. p 1-37. 
14. Bliese PD, Jex SM. Incorporating levels of analysis into occupational health research. Work Stress. 1999;13:1-6.

15. Bryk AS, Raudenbush SW. Methodology for cross-level organizational research. Res Sociolog Organ. 1989;7:233-73.

16. Stafford M, Cummins S, Macintyrec S, Ellaway SM, Marmot A. Gender differences in the associations between health and neighbourhood environment. Soc Sci Med. 2005;60:1681-92.

17. Van Emmerik HIJ. Gender differences in the creation of different types of social capital: a multilevel study. Soc Networks. 2006:28(1):24-37.

18. Härenstam A, Bejerot E, Schéele $P$, Waldenström K, Leijon $O$, MOA Research Group. Multilevel analyses of organizational change and working conditions in public and private sector. Eur J Work Organ Psychol. 2004;3:305-43.

19. Härenstam A, Rydbeck A, Karlkvist M, Waldenström K, Wiklund P, MOA Research Group. The significance of organisation for healthy work: methods, study design, analyzing strategies, and empirical results from the MOA-study. Stockholm: National Institut for Working Life; 2004. Arbete och Hälsa, number 13. p 1-89.

20. Härenstam A, Marklund S, Berntson E, Bolin M, Ylander J. Understanding the organisational impact on working conditions and health. Stockholm: National Institut for Working Life; 2006. Arbete och Hälsa [Work and Health], number 4.

21. Marklund S, Bolin M, von Essen J. Can individual health differences be explained by workplace characteristics? - a multilevel analysis. Soc Sci Med. 2008;66:650-62.

22. Bolin M, Marklund S, Bliese P. Organizational impact on psychosocial working conditions. Work. 2008:30(4):451-9.

23. Waldenström K, Härenstam A. How are good and bad jobs created? Case studies of employee, managerial and organizational factors. Work Life Transition. 2009;4:1-50.

24. Kankkunen T, Härenstam A. The gendered modernisation of public sector. In: Gender, work and organization [abstracts]. 5th Biennal International Interdisciplinary Conference; 27-29 June 2007, Keele University, Staffordshire, UK. p 1-285.

25. Israel BA, Baker EA, Goldenhar LM, Heaney CA, Schurman SJ. Occupational stress, safety, and health: a conceptual framework and principles for effective prevention interventions. J Occup Health Psychol. 1996;1:261-86.

26. Bergman LR, Magnusson D, El-Khouri BM. Studying individual development in an interindividual context: a person-oriented approach. Mahwah (NJ): Lawrence Erlbaum Associates; 2003. p 4-27.

27. Everitt BS, Landau S, Leese M. Cluster analysis. 4th ed. London: Arnold; 2001.

28. Lungren E. På jakt efter nya molekyler Nobelpristagaren arbetar vidare för att bota hjärnans sjukdomar [Searching new molecules: the Nobel Prize winner continues working in order to cure diseases of the brain][Internet]. Göteborg (Sweden): Göteborg Universtity; 2000 [cited 17 March 2009]. Available from: http://www2.gu.se/GU-journalen/7-00/nyhet7.html.

29. Donner A, Brown KS, Brasher P. A methodological review on non-therapeutic intervention trials employing cluster randomization. Int J Epidemiol. 1990;19:795-800.

30. Bumpus MF, Crouter AC, McHale SM. Work demands of dual-earner couples: implications for parents' knowledge about children's daily lives in middle childhood. J Marriage Fam. 1999;2:465-75.

31. Cinamon RG, Rich Y. Gender differences in the importance of work and family roles: implications for work-family conflict. Sex Roles. 2002;47:531-41.

32. von Eye A, Bergman L. Research strategies in developmental psychopathology: dimensional identity and the person-oriented approach. Dev Psychopathol. 2003;15:553-80.

33. Bergström G, Bodin L, Jensen IB, Linton SJ, Nygren ÅL. Long-term, non-specific spinal pain: reliable and valid subgroups of patients. Behav Res Ther. 2000;39:75-87.

34. Bergman R, Daukantaite D. The importance of social circumstances for Swedish women's subjective well-being. Int J Soc Welfare. 2006;15:27-36

35. Härenstam A, Bodin L, Karlqvist L, Nise G, Schéele P, MOAresearch group. Patterns of working and living conditions: a person-oriented, multivariate approach for occupational health studies. Work Stress. 2003;17:73-92.

36. Leijon $\mathrm{O}$, Härenstam $\mathrm{A}$, Waldenström $\mathrm{K}$, Alderling M, Vingård E. Target groups for prevention of neck/shoulder and low back disorders: an exploratory cluster analysis of working and living conditions. Work. 2006;2:189-204.

37. Leijon O, Lindberg P, Josephson M, Wiktorin C. Different working and living conditions and their associations with persistent neck/shoulder and/or low back disorders. Occup Environ Med. 2007;64:115-21.

38. Härenstam A, Berntsson E, Stjernström C. Arbetslivets många ansikten [Many faces of work life][Internet]. Göteborg (Sweden): Göteborg Universtity; 2005 [cited 17 March 2009] Available from: www.av.gu.se/profiler.

39. European Commission. Guidance on work-related stress: spice of life or kiss to death?. Brussels: Employment and Social affairs, European Commission; 2000. p 32-72.

40. Kompier MAJ, Cooper CL, Geurts SAE. A multiple case study approach to work stress prevention in Europe. Eur J Work Organ Psychol. 2000;9:371-400.

Received for publication: 5 February 2009 